\title{
Tort Liability and Alternative Approaches to Compensation: Summary of a Comparative Survey of Foreign Systems at Work
}

\author{
by Werner Pfennigstorf*
}

\section{Introduction}

\subsection{Purpose}

This report is the result of a project that has been sponsored by the All-Industry Research Advisory Council (AIRAC) and the principal purposes of which are:

- To advance the current discussion on the performance and potential reform of the American tort liability system;

- To provide a broader perspective of available options and alternative approaches;

- To deepen the understanding of competing values and public policy goals;

- To contribute to a rational resolution of policy conflicts;

- By providing up-to-date information on accident compensation systems of other countries with comparable social and economic conditions, focusing on their practical operation, interaction, cost, and effectiveness.

\subsection{Scope}

(a) The purposes just set forth call for more, and at the same time for less, than just an explanation of the rules of tort law of other countries. Less than exhaustive treatment is called for to avoid being drowned by detail. American lawyers are used to working with many different and sometimes contradictory rules in their 50-odd jurisdictions, which are at least united by a common language, national unity, common institutions, and a common heritage of basic values and legal principles. In comparison, the differences among the rules and practices of foreign countries are much greater, and they tend to be compounded by different languages and different cultural traditions. A good impression of that variety in theory and practice is provided by the two fat volumes that the International Encyclopedia of Comparative Law has devoted to Torts, written by some of the best legal minds of the world, with an abundance of references and ideas. ${ }^{1}$

* The following are the Introduction and Executive Summary of a research report prepared for the All-Industry Research Advisory Council. The full report is due to be published in the United States in the summer of 1990.

${ }^{1}$ International Encyclopedia of Comparative Law, Volume XI: Torts (André Tunc, Chief Editor). Tübingen/The Hague: J. C. B. Mohr (Paul Siebeck)/Martinus Nijhoff, 1984. 
At the same time, more than an explanation of legal rules is needed to make thee information relevant for the current American tort reform discussion. To be relevant, the rules of tort law must be viewed in the broader context of the public policies and institutions involved in accident compensation, risk spreading, and cost allocation. What that can involve is demonstrated by the work of the British Pearson Commission, which in 1978, after five years of study and hundreds of meetings in Britain and abroad, produced one 550page volume of analysis and recommendations, another 260 -page volume of statistics and cost estimates, and a third volume, about 280 pages strong, of information on other countries. The 2-volume, 1650-page Osborne Report, submitted in 1988 and dealing only with automobile accidents in the Province of Ontario, is another example of the breadth and depth of analysis attainable.

(b) AIRAC did not wish to emulate either type of in-depth analysis. It envisioned, rather, a digest-type document of manageable proportions, pulling together in one place and in usable form comparative information relating to the subject-matters and issues that have dominated the current American tort reform discussion.

This discussion is at least in part a result of what has become known as the liability crisis, or liability insurance crisis - the discovery by the public that there are substantial and growing risks of liability for which insurance coverage is not available, or available only to a limited extent and at very substantial cost. In explaining the shortage of insurance coverage, insurers have cited concern over runaway costs and unmanageable uncertainty. These concerns are in turn traced to various aspects of the liability system, and the proposed changes are expected, among other things, to limit claims, to make claims more predictable, and thereby to make insurance more available and affordable.

The areas where changes are being considered or recommended include:

- the legal rules on which liability can be based, including exceptions, statutes of limitations, presumptions, and burdens of proof ;

- the legal rules determining the kind and amount of compensable damages, including such issues as nonpecuniary damages and punitive damages;

- procedural rules and practices, including those relating to trial by jury, evidence, allocation of costs and fees, and alternatives to civil litigation;

- factors and attitudes influencing judges and juries in determining liability and the amount of damages to be awarded;

- the responsiveness of the insurance market;

- availability and extent of alternative sources of compensation and their effect on tort liability.

While earlier crises and reform movements tended to focus on claims arising from bodily injury caused by accident, and more specifically by automobile accidents, the present discussion in the U.S. is dominated by other areas of liability, notably liability for defective products, for failure to observe professional standards of care, and for contamination of the environment.

These types of liability, which are not limited to bodily injury, present new issues of public policy. In the past, the strongest forces of expansion of compensation, through tort liability or otherwise, were associated either with a sense of responsibility of society to care 
for those individuals who became needy through no fault of their own, or with the emotional appeal of the personal suffering of injury "victims".

This particular appeal is not present, or at least not as strong, where property damage or "pure" economic loss is concerned. This may in part explain why many alternative compensation schemes limit compensation to losses caused by bodily injury.

That there are other forces, of a strength not to be ignored, is shown by the attention devoted to physical damage to motor vehicles and recently to the various economic losses associated with pollution of the environment and with the violation of duties by professionals or by directors or officers.

Expectations concerning the amount and significance of the information available about other countries on these points should not be set too high, though. In the U.S., the unpredictability of liability and the resulting problems of insurability can in part be explained by the fact that in the areas under discussion the law is in a relatively early stage of development. In time, as the law advances, liability can be expected to become more predictable. This is also true, as a rule, for other countries. Consequently, such experience as there is must be viewed with caution.

Other parts of the system are more stable, and with respect to them, comparative information about other countries can be expected to be more meaningful. This is true especially for procedural aspects and for the role of alternative sources of compensation.

As the American discussion is dominated by concerns over cost and predictability, readers of this survey are likely to be particularly interested in factual information on the dimensions of liability and liability insurance and on the dynamics of change. Information of this kind is difficult to find in other countries, however. As the experience of the U.S. has shown, insurers and public agencies are not likely to collect information (especially statistical data) until becoming aware of a problem of major proportions with political implications. Since in other countries there is no perception of a liability or insurance "crisis", interest in related information has not emerged on a scale comparable to that in the U.S. Where insurers in other countries have relevant information, they are not always ready to share it.

Where information can be found it is often of a kind that precludes or impedes easy comparison. There are great differences in the kinds of data collected, in the purposes for which they are collected, the methods of collection and analysis, the definitions used, and the reliability of the sources.

The inherent limits of comparability are compounded by the fact that interpretation of the data here and there tends to be influenced by the standpoint of the observer. Thus, as the discussion within the U.S. shows, there are some basic differences of position, of an almost ideological nature, that make it difficult to agree on objective criteria for deciding whether a given system "works", just as there is no agreement on what "full compensation" means.

Keeping these limitations in mind, it seems possible, nevertheless, to compile some data and facts that may serve as a basis for evaluating the effectiveness and efficiency of the various systems. In addition to basic information on accidents, losses, and claims, different sources of compensation and their coordination, these include data or estimates on litigation rates and settlement costs. 
It is equally important to recognize that compensation and liability systems are not static but are continuously changing in response to social, economic, and political pressures. This is true for the countries surveyed here no less than for the U.S. To account for these dynamic elements, this survey includes information on changes that were made in the recent past, on changes that were recently proposed but rejected, and on current criticisms and proposals for change in the future.

The information about changes made or proposed is useful in two ways: first, as an indicator of gaps or weaknesses in the system or of shifts in public perception of values or political power and second, by implication, as an indicator of satisfaction and acceptance, as every criticism and every proposal of change by necessity includes a statement about those features of the system that are considered satisfactory and therefore in no need for change or even discussion.

In addition, this survey takes note of other available indicators of satisfaction, acceptance, and potential change, for instance in the form of existing and changing public attitudes as reflected in opinion surveys. This is done with no claim to meeting the rigorous standards of social science methodology.

(c) The survey must also be limited with respect to the countries included. The following were selected:

$\begin{array}{ll}\text { Australia } & \text { Federal Republic of Germany } \\ \text { Canada } & \text { France } \\ \text { New Zealand } & \text { The Netherlands } \\ \text { United Kingdom } & \text { Sweden } \\ \text { Japan } & \text { Switzerland }\end{array}$

Hereafter, the Federal Republic of Germany will be referred to as Germany, the United Kingdom will be abbreviated U.K., and the United States will be abbreviated U.S. The European Communities, of which France, Germany, the Netherlands, and the U.K. are members, will be abbreviated E.C.

Summaries of the basic legal framework of each of the countries, so far as relevant for this survey, are provided in Chapter II.

Relevance and variety were the principal considerations in making the selection. All of the countries are economically well developed and like the U.S. hold positions at the upper end of the standard of living scale. They also share the U.S. basic political and economic philosophies. It is no accident, therefore, that the list ist almost identical to that of the countries studied by the Pearson Commission. Only Japan is new to this study. All the countries studied are smaller than the U.S. in population, by a wide margin, and most (except Canada, which is slightly larger, and Australia, which is almost as large) are also much smaller in area.

There is much variety in legal systems. Four of the countries belong to the Common Law family, five are in the European civil law tradition;2 Japan had grafted, on its own

2 The Common Law / Civil Law classification is of old standing but is difficult to frame in precise and uniformly applicable criteria. It is most often expressed in terms of the relative roles of the courts and the legislature in establishing and developing the basic principles of the law. Civil Law Systems are usually associated with great codes. Related to this basic difference, there are other differences con- 
ancient cultural tradition, the concepts and methods of European civil law but lately has also borrowed heavily from the U.S.

Australia, Canada, Germany, and Switzerland are federal systems like the U.S. but with different approaches to allocating powers and responsibilities. The U.K., although not a federal system in the strict sense, has preserved different legal traditions in England and Wales, Scotland, and Northern Ireland. A rich and fascinating variety of approaches has developed in these nations, especially in the area of accident compensation. Here, too, however, considerations of space and clarity require that a selection be made.

New Zealand is known to have gone farthest in replacing tort liability with a universal system of accident compensation. Its closest follower appears to be Sweden. The other countries have gone different ways and different distances in their efforts to secure fast, equitable compensation for those injured in automobile accidents and other frequently occurring types of accidents at low cost and to minimize for those accidents the likelihood of costly and time-consuming litigation.

Comparison among the countries is, of course, intended, at least to some extent. It should be undertaken with great caution, however, especially where figures are provided, keeping in mind the dissimilar sources and quality of the data.

This survey is intended for an Americana audience generally interested in the subject of tort law reform. Consequently, readers are assumed to be generally familiar with the American tort and insurance system. American rules and practices are referred to only occasionally where it seems useful in explaining a noteworthy feature of a foreign system.

\subsection{Approach and organization}

This project was not conceived as one involving original empirical research but rather as one of pulling together and organizing existing information from scattered sources. Most of the information is from publications; in addition, data and estimates have been collected wherever they could be found, including interviews and inquiries with practitioners in the fields involved.

As noted earlier, information is not uniformly available on all subjects in all countries. Besides, the breadth of the survey, both with respect to subject-matter and with respect to jurisdictions covered, makes exhaustive coverage inopportune. Consequently, in discussing the various aspects of the liability system, not all jurisdictions are mentioned each time. As a rule, the rules, practices, and cases cited are believed to be representative of at least some of the countries. The emphasis is on showing both similarity and variety of perceptions and approaches in general qualitative terms. No attempt is made to measure the differences among the countries in any quantitative way.

If some jurisdictions are mentioned more frequently than others, that is due primarily to the fact that information on them has been more readily available. If on a particular subject a particular jurisdiction is not mentioned specifically, it may mean one of several

cerning the role of lawyers, the style of legal reasoning, and the deference accorded case law as compared to statutory law. Under the pressure of common political and economic developments, some of the traditional differences have been eroding. Nevertheless, the traditional classification still offers a convenient way to categorize a variety of legal institutions and practical approaches. See, e.g., John Merryman, Civil Law Tradition, in 35 Am. J. Comp. L. 438 (1987). 
things - that the particular issue is irrelevant, or that the situation is similar to the ones mentioned, or that no information could be obtained on that jurisdiction. An effort has been made to leave no doubt about which af these possibilities applies.

Chapter II presents summaries of the basic legal and procedural frameworks of each country, to the extent that such information seems necessary for understanding the discussion of specific aspects in the chapters that follow. More background information, concerning basic demographic and economic data, is provided in Appendix A.

Chapter III is devoted to the essential elements of tort liability. This is followed in Chapter IV by a discussion of the role of liability insurance. Chapter V deals with alternative sources of compensation: social security, private first-party insurance, and special compensation programs. Chapter VI examines the coordination of benefits, with special emphasis on the rules and practices of subrogation. Chapter VII deals with settlement and litigation, and Chapter VIII deals with costs and related data. The last chapter seeks to identify the most significant forces that have shaped the tort and compensation system in the recent past and can be expected to produce further changes in the future.

To save space and improve readability, references in the text, as well as notes (to be found in Appendix D), have been kept to a minimum. Selected references to relevant publications in English are provided in Appendix B. As a very large part of the factual information is from non-English sources, the more important ones among those are also listed, in Appendix C.

\section{Executive Summary}

As one of its contributions to the old and still urgent subject of tort law reform, AIRAC commissioned this survey of the law and practice of liability and compensation in ten foreign countries.

The countries included in the survey are: Australia, Canada, the Federal Republic of Germany, France, Japan, the Netherlands, New Zealand, Sweden, Switzerland, and the United Kingdom. They were selected in part on the basis of having political and economic philosophies similar to the U.S., in part on the basis of having adopted different approaches to the problem of liability and compensation, and in part on the basis of availability of relevant information.

The survey is intended to provide a broader and more reliable basis for the discussion of alternatives to the traditional American patterns of liability and compensation. To that end, the information collected for the ten countries is not limited to legal rules but includes as much data on the practical operation of the respective systems as could be obtained. On the other hand, the survey is also limited by its particular purpose. It does not aspire to being an exhaustive treatise of the foreign systems.

The survey does not suggest that any feature of a foreign system may be suitable for adoption in the U.S. or may work here in the same way as it does in the respective country. The survey does suggest, however, that the American tort reform discussion would benefit from a careful look at the ideas developed in other countries and the experiences gathered there with alternative approaches.

Generally, comparative evaluation of the foreign systems should be undertaken with great caution and with the basic differences between the various countries in mind. To 
facilitate meaningful comparison, the survey includes (in Appendix A) a collection of basic demographic and economic data.

The survey starts with short summaries of the ten countries. This is followed by chapters devoted to relevant rules of liability, liability insurance, alternative sources of compensation, coordination of sources, and procedure. Chapter VIII contains statistical data on accidents, claims settlement, litigation, and the economic impact of liability. The concluding chapter discusses the major forces driving the development, possible explanations of some of the differences among the countries, and the potential for change.

Among the observations in the survey, the following are especially noteworthy:

No softer stance on liability. The survey does not support the view that the rules of liability of other countries are generally less stringent than those of the U.S. In some respects, they appear to be stricter. Notably, strict liability has been a common feature, on the basis of statute or case law, for railroads, automobiles, aircraft, and certain dangerous activities.

The members of the European Communities are in the process of adopting strict liability for defective products; a number of other countries are doing the same. There are plans to expand strict liability for environmental pollution.

Where strict liability is not imposed expressly, the courts have frequently reached equivalent results by reversing the burden of proof or by imposing exceedingly strict duties of care.

Government units do not, as a rule, enjoy more lenient standards. In England, the government was held responsible for damage done by juvenile offenders who had not been properly supervised; in Germany, local governments must pay for accident claims if vehicle licensing offices do not act immediately to invalidate the license plates of uninsured vehicles.

In some countries, notably the U.K., medical malpractice claims have recently increased at an alarming rate.

The rule of joint and several liability is generally recognized and apparently has not caused unacceptable problems. The injured person's own negligence is considered everywhere in a rule equivalent to comparative negligence. A few countries (Netherlands, Sweden) provide for mitigation of damages in view of the financial circumstances of the parties (including the existence of liability insurance coverage).

Restraints in measuring damages. Generally, lawyers and courts of other countries appear to be no less imaginative than those of the U.S. in finding new kinds of recoverable damages. This is true especially for losses due to bodily injury. There is a confusing variety of items of nonpecuniary loss, and of measuring them.

The amounts awarded, however, are more predictable. Courts, deciding without a jury, tend to observe written or unwritten schedules or guidelines. In some countries (Japan, Sweden), special commissions of experts have been established for automobile accident and certain other claims to ensure consistency. While the general level of awards is rising steadily, it does so in relatively small increments. There are no extreme awards of the kind that appear in American headlines.

Also, punitive or exemplary damages are not recognized except to some extent in the U.K. and in New Zealand. 
Large variety of alternative compensation sources. The survey notes that practically everywhere medical treatment and hospital care are provided under social security programs and often in kind, and thus do not even appear as items of damage claims. Work accident compensation also is part of the social security system in many countries. In a unique approach, the Netherlands have abandoned the distinction between accidents (whether work-related or not) and diseases and thus provide identical benefits in identical procedures in all cases of disability regardless of the cause.

In discussing the well-known comprehensive accident compensation scheme of New Zealand, the survey notes its pioneering role in compensating non-work accidents. It also notes the administrative and financial problems that have resulted from its failure to include ordinary diseases and from its lump-sum benefit features, and the recent efforts to deal with an unanticipated increase in claims volume.

While the New Zealand scheme is a government program, the Swedish alternative relies on voluntary private first-party insurance. So far, three schemes have been established: for work accidents, for medical care injuries, and for injuries caused by pharmaceutical drugs. These schemes are unique in several respects, notably in that they provide benefits on the standards of damages recoverable under tort law. Further, the schemes rely on expert screening panels both for determining whether a claim is eligible for compensation and for determining the amount of compensation. The principal standard is that of "reasonableness". Although court actions are not precluded, it appears that the decisions of the panels are commonly accepted as final. A similar approach is used for claims under the (compulsory) automobile insurance scheme.

In some cases where social policy demands compensation (vaccination, students, other activities in the public interest), some countries (notably France, Germany, and Switzerland) use the standards and procedures of their existing work accident or other social security programs to provide benefits.

Coordination of compensation sources. Compensation received from other sources is commonly considered in computing damages, to the extent that it corresponds precisely to specific items of compensable loss. Consequently, damage claims of individuals are mostly for minor residual losses and for nonpecuniary damages.

Subrogation was abolished for economic reasons in Sweden but is provided by statute and considered very important in some other countries. In Germany, social security carriers and liability insurers have concluded settlement agreements providing for standard percentages. A bulk subrogation agreement also exists in the Canadian province of Ontario.

Cost allocation on a broader scale is prescribed by statute in France, where automobile liability insurers must collect a surcharge of $15 \%$ and transmit the proceeds to social health insurance carriers.

In litigation, the most notable differences between the countries in the survey and the U.S. appear to be: (1) the less pronounced adversarial nature of proceedings, (2) the absence of juries, (3) absence of contingent fees, (4) generally a common disposition both among claimants and among insurers to negotiate rather than litigate.

Litigation costs are imposed on the losing party. In most countries, this includes all attorney fees, except in Japan, where attorney fees are not shifted at all, and in France, the 
Netherlands, and Sweden, where only a part is shifted to the loser. In the European countries, legal expense insurance is available and is widely used to finance lawsuits, and there has been some concern about abuses.

Claims and litigation rates have increased over the past several years but generally not at an alarming rate.

There has been no perception of a crisis anywhere (except to some extent in Canada) comparable to the liability and insurance crisis of the U.S.

Specifically, there have not been (except to some extent in Canada) any severe disruptions of coverage due to wholesale cancellations or withdrawals of insurers from the market.

Generally, availability of insurance protection does not appear to be a problem anywhere outside the U.S. In some countries (Australia, Canada, France, Germany, Switzerland), the traditional involvement of governments in fire insurance and automobile insurance may be a factor. In addition, a German law prohibits automobile insurers from rejecting applications except for a limited number of reasons. France has a placement program for required automobile insurance. In the other countries, however, no such rules have been considered necessary.

Accordingly, criticism and demands for change are limited to specific aspects of existing systems, rather than the basic design.

For the future, further expansion of the claims volume is expected, but it is expected that the existing liability and compensation systems will be able to handle it without major difficulties. With few exceptions (medical malpractice in the U.K.), current proposals for changes in the tort law are directed at expanding rather than restricting liability. 